\title{
Carrying G allele in rs786204926 involved in alternative splicing of PTEN is associated with chemosensitivity in breast cancer
}

\author{
Jing Wang \\ Lanzhou University \\ Shasha Zhang \\ Lanzhou University \\ Jiaxin Zhang \\ Lanzhou Jiaotong University

\section{Zhongliang Zhang} \\ First People's Hospital of Lanzhou City \\ Qinglong Ma \\ Lanzhou University

\section{Wenkang Fu} \\ Lanzhou University First Affiliated Hospital \\ Xiaohua Chen \\ Chinese Academy of Sciences

\section{Dapeng Zhao} \\ Chinese Academy of Sciences \\ Meie Zhao \\ Lanzhou University

\section{Chunwei Wang} \\ Gansu Provincial Hospital

\section{Cuixia Di} \\ Chinese Academy of Sciences \\ Xiaodong Xie ( $\sim$ xdxie@lzu.edu.cn ) \\ Lanzhou University
}

\section{Research}

Keywords: PTEN, single nucleotide polymorphism, chemosensitivity, alternative splicing, breast cancer, silico analysis

Posted Date: October 5th, 2021

DOl: https://doi.org/10.21203/rs.3.rs-934220/v1 
License: @ (1) This work is licensed under a Creative Commons Attribution 4.0 International License. Read Full License 


\section{Abstract \\ Background}

Chemoresistance is still the main reason for the failure of breast cancer treatment and is the main cause of death of breast cancer patients. Although many studies have shown the association between genetic polymorphisms of PTEN and chemoresistance, the molecular mechanism of breast cancer chemotherapy has not been further studied. This study aims to investigate the potential association between novel PTEN gene polymorphism and breast chemoresistance in Chinese population, and explore whether alternative splicing of the PTEN gene is affected by the gene polymorphism.

\section{Methods}

The study included 234 patients with breast cancer chemotherapy, 157 chemosensitive cases and 77 chemoresistant case. rs786204926, rs701848, rs12402181, rs35770269 were analysed using Sanger sequence and Sequenom MassArray typing technology. Silicon analysis was used to predict whether and how the polymorphism affects alternative splicing. Semi-quantitative RT-PCR and Western blot were further used to validate the silicon analysis.

\section{Results}

It is showed that there was a significant association between rs786204926 polymorphism and breast cancer chemoresistance. Carrying G allele or AG genotype will increase the risk of chemosensitivity in breast cancer. Additionally, Logistic multivariate regression analysis showed that age, lymph node metastasis and rs786204926 genotype are risk factors for breast cancer chemoresistance. Furthermore, Silico analysis showed that carrying $\mathrm{G}$ allele or $\mathrm{AG}$ genotype in chemosensitivity samples produced a new receptor site of alternative splicing, which increases the possibility of a new mutant PTEN isoform production. Interestingly, further experiments also verify this possibility.

\section{Conclusion}

We speculate that the mechanism of breast cancer chemosensitivity might be caused by a change in alternative splicing caused by the rs786204926 of PTEN gene. Thus, our study might provide theoretical guidance for the individualized treatment of clinical breast cancer patients.

\section{Background}

Breast cancer is a malignant tumour that occurs in breast epithelial tissue and is the most common malignant tumour in women[1]. Breast cancer has become a serious health problem threatening women all over the world[2, 3]. Although chemotherapy is one of the main treatments for breast cancer, chemoresistance is still the main reason for the failure of breast cancer treatments[4-6]. Therefore, the identification of genetic mechanisms involved in chemoresistance is crucial for predicting the drug response of tumour with genetic mutations[7, 8]. 
Studies have reported that the key mutation of the tumour suppressor gene might be the main factor of drug resistance in the treatment for cancer patients[9-11].

Currently, there are many tumour suppressor genes involved in breast cancer chemoresistance, including MDR1, ABCG2 and PTEN[12-14]. The PTEN gene is one of the most common tumour suppressor genes and is a phosphatase which dephosphorylates phosphatidylinositol $(3,4,5)$-triphosphate (Ptdlns-3,4,5-P3), lowering its level within the cell. Ptdlns-3,4,5-P3 is necessary for the activation of Akt, a serine/threonine kinase involved in cell growth and survival. By blocking the activation of Akt, PTEN regulates cellular processes such as cell cycling, translation, and apoptosis[15]. Many studies have reported that PTEN is associated with resistance to chemotherapy drugs such as adriamycin[16], paclitaxel[17], cisplatin[18], tamoxifen[19] and trastuzumab[20] in breast cancer. The PTEN gene has multiple single nucleotide polymorphism (SNP) and is a highly polymorphic gene, and pathogenic germline mutations are found in all 9 exons[21]. It is still need to find novel SNP of PTEN gene related to chemoresistance, and study how the polymorphism affects chemoresistance. In recent years there are some reports that polymorphism can affect the process of alternative splicing (AS), which lead to the occurrence and development of human diseases[22-25]. A small number of studies have found that the PTEN gene can produce new isoforms, such as retained intron 3 regions ( $3 a, 3 b, 3 c)$ and intron 5 regions (5a, 5b, 5c); excluded part of exon 5 (DelE5) or all of exon 6 (DelE6); PTENa and PTEN $\beta[26,27]$, but the abnormal AS of PTEN gene about chemoresistance is not reported.

Although many studies have shown the association between genetic polymorphisms of PTEN and drug resistance[28, 29], the underlying molecular mechanism of PTEN gene polymorphism leading to breast cancer chemoresistance is still unclear. As far as we know, mutations in specific sites of genes can cause certain diseases and affect the AS process of genes, but the association between SNP and AS of PTEN in Chinese population with the risk of breast cancer chemoresistance has not been reported. Therefore, this study aims to explore the molecular mechanism of the potential relationship between novel PTEN gene polymorphism and breast chemoresistance. Our work might provide theoretical guidance for individualized treatment of breast cancer chemotherapy in Chinese population.

\section{Materials And Methods}

\section{Study population}

This study enrolled 234 blood samples and randomly selected 9 tissue samples, all from the former Lanzhou General Hospital of Lanzhou Military Region between September 2013 and April 2020. All samples were clinically diagnosed and received chemotherapy. All chemotherapy regimens were based on anthracyclines, samples who had not received treatment, did not use anthracyclines, or treated less than 2 courses were excluded. Usually anthracycline-based chemotherapy regimens consist of 5-fluorouracil (5-FU), anthracycline compounds and cyclophosphamide (FAC-FEC-EC or AC regimen). After treatment, the chemotherapy efficacy after anthracycline treatment was evaluated and scored according to the Response Evaluation Criteria in Solid Tumour (RECIST) criteria[30]. In this study, chemosensitivity were considered as patients with complete or partial remission, and patients with stable or progressing disease were classified as chemoresistance. The ethics committee of Lanzhou University School of Basic Medicine approved the study.

\section{Extraction of genomic DNA and genotyping}


Collected peripheral blood of all samples in sterile tubes with EDTA and stored at $-80^{\circ} \mathrm{C}$. Used the phenol/chloroform method to isolate genomic DNA from white blood cells. The extracted DNA was stored at $-80^{\circ} \mathrm{C}$ until use. The concentration and purity of DNA were measured using NanoDrop 2000c spectrophotometer (Thermo Fisher Scientific, Lenexa, KS, USA). Four SNPs (rs786204926, rs701848, rs12402181, rs35770269) were genotyped using Sequenom MassArray typing technology for samples with a DNA concentration of more than 20ng/ $\mu$ l (Beijing Bomiao Biotechnology Co., Ltd., China). Used Assay Design 3.1 software to design the primers required for Sequenom MassArray (Supplementary Table 1). After PCR amplification reaction, SAP-PCR reaction, purification reaction, and spotting the purified extension product, Spectro CHIP was prepared. After spotting, used MALDI-TOF mass spectrometer to detect Spectro CHIP, and used TYPER 4.0 software to analyse the results.

\section{Sequencing verification}

Randomly selected $10 \%$ of samples for verification. The primers were designed and sent to the company (General Biosystems (Anhui) Co., Ltd., China) for synthesis. The primers were shown in Supplementary Table 2. The PCR reaction program consists of 31 cycles, $94^{\circ} \mathrm{C} 3 \mathrm{~min} ; 94^{\circ} \mathrm{C} 30 \mathrm{~s}$; annealing temperature: $58.8^{\circ} \mathrm{C}, 58^{\circ} \mathrm{C}$, $58^{\circ} \mathrm{C}, 58^{\circ} \mathrm{C} 30 \mathrm{~s} ; 72^{\circ} \mathrm{C} 25 \mathrm{~s} ; 72^{\circ} \mathrm{C} 5 \mathrm{~min}$ (rs786204926, rs701848, rs 12402181, rs35770269). The synthesized products were electrophoresed on a $1 \%$ agarose gel. The PCR amplified products were verified by sequencing (General Biosystems (Anhui) Co., Ltd., China).

\section{Semi-quantitative RT-PCR and sequencing}

We randomly selected 6 breast cancer tissues samples after chemotherapy. Total RNA was extracted from the tissue using TRIzol (Invitrogen, Carlsbad, CA, USA), and cDNA was reverse transcribed using RT MasterMix (Cwbiotech, Beijing, China). PCR amplification of the cDNA using primers: PTEN-Wild-F:

AATTGCAGAGTTGCACAATATCC; PTEN-Mutation-F: GTTATCTTTTTACCACGGTTGC; PTEN R: GTCTCTGGTCCTTACTTCCCC; PCR was initially activated at $94^{\circ} \mathrm{C}$ for $3 \mathrm{~min}$, followed by 32 cycles of 30 s at $94^{\circ}$ $\mathrm{C} ; 30 \mathrm{~s}$ at $60^{\circ} \mathrm{C} ; 25 \mathrm{~s}$ at $72^{\circ} \mathrm{C}$; finally at $72^{\circ} \mathrm{C}$ Extend for $5 \mathrm{~min}$. Analysed the product on a $1 \%$ agarose gel and used Quanity One software for quantitative analysis. PCR amplified products were verified by sequencing (General Biosystems (Anhui) Co., Ltd.).

\section{Western blot analysis}

We randomly selected 9 breast cancer tissues samples after chemotherapy. The total protein was extracted using radio immunoprecipitation assay lysis buffer (Beyotime Biotechnology, Shanghai, China), and the protein concentration was measured using a protein concentration determination kit (Solarbio, Beijing, China). Then the proteins were quantified according to different concentrations, separated by polyacrylamide gel electrophoresis, and transferred to the polyvinylidene fluoride membrane (Millipore, Billerica, MA, USA). The membrane was incubated with diluted anti-human primary antibody overnight at $4^{\circ} \mathrm{C}$ to phosphorylate $\mathrm{PI} 3 \mathrm{~K}(1: 1000 ; 20584-1$ AP), ASF/SF2 (1:1000; 12929-2-AP), PTEN (1:1000; 22034-1-AP), SFRS5 (1:1000; 16237-1-AP), and GAPDH $(1: 2000 ; 60004-1-\mathrm{lg})$. After the membrane was supplemented with horseradish peroxidase-labeled goat antirabbit IgG (1:3000; S0001) and used chemiluminescence kit (NCM Biotech Co., Ltd., Suzhou China). The protein was then quantified using ImageJ software (National Institutes of Health, Bethesda, Maryland, USA). The relative protein expression is expressed by the gray value of the target band and GAPDH.

\section{In silico analysis}


In order to study the correlation between PTEN mutant genome and epirubicin drug sensitivity in breast cancer, we used Genomics of Drug Sensitivity in Cancer version 8.3 (GDSC, https://www.cancerrxgene.org/)[31]. In order to predict whether rs786204926 affects the splicing site and splicing position changes, we used Alamut Visual v.2.15 and Human Splicing Finder (HSF, https://www.genomnis.com/access-hsf) conducted a silico analysis. cDNA and protein sequence refer to Ensembl Release 102 and NCBI database. To translate cDNA sequence into amino acid sequence, we used online tool: https://www.novopro.cn/tools/translate.html. We searched for PTEN (PDB ID: 5BUG) and INS (1,3,4,5) P4 (PDB ID: 1BWN)[32] protein crystal structures through the PDB (https://www.rcsb.org/) database, used Pymol 2.3.0 to perform single point mutations on PTEN and used Zdock for docking; Used Pymol 2.3.0 for interaction mode analysis.

\section{Statistical analysis}

The Hardy-Weinberg balance test was performed on the allele frequency of rs786204926, rs701848, rs12402181, rs35770269 and the $\chi 2$ test was used to determine whether the difference was statistically significant, $P<0.01$ was considered statistically significant. The clinical data and genotyping results were analysed using SPSS 22.0 software (IBM Corp., Armonk, NY, USA), used independent sample t-test, chi-square test, and Fisher's exact test (sample size<5), $P<0.05$ was considered statistically significant. Logistic regression analysis was used to evaluate the correlation between the relevant factors and the occurrence of chemosensitivity. Data were presented as the mean \pm SD and analysed with SPSS 22.0 and GraphPad Prism 5.0. The differences between two groups were analysed with Student's t-test.

\section{Results}

\section{Distributions of the clinical characteristics in breast cancer patients}

The study included 234 breast cancer patients with 157 (67.1\%) chemosensitive and 77 (32.9\%) chemoresistant. Figure $1 \mathrm{~A}$ is the imagological examination data of chemosensitivity and chemoresistance. Table 1 showed the clinical characteristics and statistical information of 234 patients. All participants are female, with the median age of 48 years. According to American Joint Committee on Cancer (AJCC) Clinical Stage, most patients were diagnosed with stage II or stage III breast cancer. Pathological examination revealed 222 cases of invasive ductal carcinoma (94.9\%). There were statistical differences in Histological type, PR, and Molecular Subtype between the sensitive group and the resistant group $(P<0.05)$, and no significant difference was found in the other variables between the two groups ( $P>0.05)$. 
Table 1

Characteristics of study subjects.

\begin{tabular}{|c|c|c|c|c|}
\hline Characteristics & Total & Chemosensitive & Chemoresistant & $P$ \\
\hline & 234 & $157(0.671)$ & $77(0.329)$ & \\
\hline Age (years) & & & & 0.244 \\
\hline$<48$ & $113(0.483)$ & $80(0.510)$ & $33(0.429)$ & \\
\hline$\geq 48$ & $121(0.517)$ & $77(0.490)$ & $44(0.571)$ & \\
\hline Menopausal state & & & & 0.421 \\
\hline Menopause & $68(0.291)$ & $43(0.274)$ & $25(0.325)$ & \\
\hline Premenopausal & $166(0.709)$ & $114(0.726)$ & $52(0.675)$ & \\
\hline AJCC Clinical Stage & & & & 0.395 \\
\hline ॥ & $104(0.444)$ & $64(0.408)$ & $40(0.519)$ & \\
\hline IIIA & $51(0.218)$ & $38(0.242)$ & $13(0.169)$ & \\
\hline IIIB & $65(0.278)$ & $45(0.287)$ & $20(0.260)$ & \\
\hline $\mathrm{IIIC}+\mathrm{IV}$ & $14(0.060)$ & $10(0.064)$ & $4(0.052)$ & \\
\hline Histological type & & & & $0.011 *$ \\
\hline Invasive ductal carcinoma & $222(0.949)$ & $153(0.975)$ & $69(0.896)$ & \\
\hline Other types & $12(0.051)$ & $4(0.025)$ & $8(0.104)$ & \\
\hline Tumor size & & & & 0.455 \\
\hline $\mathrm{T} 1($ size $\leq 2)$ & $64(0.274)$ & $39(0.248)$ & $25(0.325)$ & \\
\hline T2 (2ロsize $\leq 5)$ & $94(0.402)$ & $66(0.420)$ & $28(0.364)$ & \\
\hline T3(size邓5) & $76(0.325)$ & $52(0.331)$ & $24(0.312)$ & \\
\hline Lymph node staging & & & & 0.981 \\
\hline NO & $79(0.338)$ & $53(0.338)$ & $26(0.338)$ & \\
\hline N1 & $81(0.346)$ & $55(0.350)$ & $26(0.338)$ & \\
\hline N2 & $58(0.248)$ & $39(0.248)$ & $19(0.247)$ & \\
\hline N3 & $16(0.068)$ & $10(0.064)$ & $6(0.078)$ & \\
\hline ER & & & & 0.181 \\
\hline Negative & $124(0.530)$ & $88(0.561)$ & $36(0.468)$ & \\
\hline
\end{tabular}

a C-erbB-2-positive: HER2 (+++) or Fish (+); ER, estrogen receptor; PR, progesterone receptor; C-erbB-2, human epidermal growth factor receptor 2 .

*: $P$ value $<0.05$ was considered as significant. 


\begin{tabular}{|c|c|c|c|c|}
\hline Characteristics & Total & Chemosensitive & Chemoresistant & $P$ \\
\hline Positive & $110(0.470)$ & $69(0.439)$ & $41(0.532)$ & \\
\hline PR & & & & $0.015^{*}$ \\
\hline Negative & $70(0.299)$ & $55(0.350)$ & $15(0.195)$ & \\
\hline Positive & $164(0.701)$ & $102(0.650)$ & $62(0.805)$ & \\
\hline C-erbB-2 ${ }^{a}$ & & & & 0.830 \\
\hline Negative & $32(0.137)$ & $22(0.140)$ & $10(0.130)$ & \\
\hline Positive & $202(0.863)$ & $135(0.860)$ & $67(0.870)$ & \\
\hline Molecular Subtype & & & & $0.041^{*}$ \\
\hline Luminal A & $50(0.214)$ & $29(0.185)$ & $21(0.273)$ & \\
\hline Luminal B & $131(0.560)$ & $98(0.624)$ & $33(0.429)$ & \\
\hline HER2 overexpression & $19(0.081)$ & $10(0.064)$ & $9(0.117)$ & \\
\hline Triple-negative & $34(0.145)$ & $20(0.127)$ & $14(0.182)$ & \\
\hline \multicolumn{5}{|c|}{$\begin{array}{l}\text { a C-erbB-2-positive: HER2 (+++) or Fish (+); ER, estrogen receptor; PR, progesterone receptor; C-erbB-2, human } \\
\text { epidermal growth factor receptor } 2 \text {. }\end{array}$} \\
\hline \multicolumn{5}{|c|}{ *: $P$ value $<0.05$ was considered as significant. } \\
\hline
\end{tabular}

\section{Statistical Analysis Of Four Snps Genotyping Results}

MassArray genotyping was performed on the rs786204926, rs701848, rs12402181, rs35770269 polymorphism of 234 patients. We analysed the genotype frequency of SNP, rs786204926, rs701848, rs35770269 accords with the HW equilibrium state (Table 2). We further statistically analysed the genotype results and compared the distribution of genotypes under different genetic models. The results were listed in Table 3 . In the heterozygote model, the AG genotype was significantly different from the AA genotype ( $O R=0.497,95 \% \mathrm{Cl}=0.265-0.933$, $P=0.002)$. Under the Dominant model, the $A G+G G$ genotype was significantly different from the AA genotype (OR=0.472, 95\% $\mathrm{Cl}=0.263-0.848, P=0.011)$. In the allele analysis, there was a statistical difference between alleles $\mathrm{G}$ and $\mathrm{A}(\mathrm{OR}=0.522,95 \% \mathrm{Cl}=0.320-0.850, P=0.008)$, Carrying the $\mathrm{G}$ allele or $\mathrm{AG}$ genotype will increase the risk of chemosensitivity in breast cancer. We further subgroup analysis showed that rs786204926 was associated with age ( $\geq 48$ ), premenopausal, AJCC Clinical Stage II, molecular subtype (HER2 overexpression, triple-negative) in breast cancer chemoresistance (Supplementary Table 3). There is no correlation between rs701848, rs 12402181, rs35770269 and breast cancer chemosensitivity. We randomly selected some samples to verify the genotyping results using Sanger sequencing method. Figure 1B showed the image of PCR products of some samples after agarose gel electrophoresis. The wild homozygous, heterozygous, and mutant homozygous sequence of the rs786204926 polymorphism were shown in Figure 1C. 
Table 2

The test of Hardy-Weinberg Equilibrium of four SNPs.

\begin{tabular}{|llllll|}
\hline SNP & Group & Genotype & & \multicolumn{2}{c|}{ P } \\
\cline { 3 - 5 } & & 11 & 12 & 22 & \\
\hline rs786204926 & Chemosensitive & $85(54.1 \%)$ & $56(35.7 \%)$ & $16(10.2 \%)$ & 0.147 \\
\hline & Chemoresistant & $55(71.4 \%)$ & $18(23.4 \%)$ & $4(5.2 \%)$ & 0.143 \\
\hline rs701848 & Chemosensitive & $57(36.9 \%)$ & $67(43.3 \%)$ & $33(19.7 \%)$ & 0.114 \\
\hline rs12402181 & Chemosensitive & $60(38.2 \%)$ & $89(56.7 \%)$ & $8(5.1 \%)$ & 0.001 \\
\hline & Chemoresistant & $33(42.9 \%)$ & $35(45.5 \%)$ & $9(11.7 \%)$ & 0.952 \\
\hline rs35770269 & Chemosensitive & $54(34.4 \%)$ & $73(46.5 \%)$ & $30(19.1 \%)$ & 0.549 \\
\hline & Chemoresistant & $34(44.2 \%)$ & $34(44.2 \%)$ & $9(11.7 \%)$ & 0.910 \\
\hline
\end{tabular}


Table 3

The association between PTEN gene polymorphisms and the risk of breast cancer chemotherapy resistance.

\begin{tabular}{|c|c|c|c|c|c|c|}
\hline SNP & Model & Allele/Genotype & Chemosensitive & Chemoresistant & $\begin{array}{l}\text { OR } \\
(95 \% \mathrm{Cl})\end{array}$ & $P$ \\
\hline \multirow[t]{12}{*}{ rs786204926 } & Heterozygote & $\mathrm{AA}$ & $85(0.541)$ & $55(0.714)$ & & \\
\hline & & $A G$ & $56(0.357)$ & $18(0.234)$ & $\begin{array}{l}0.497 \\
(0.265- \\
0.933)\end{array}$ & 0.028 \\
\hline & Homozygote & $\mathrm{AA}$ & $85(0.541)$ & $55(0.714)$ & & \\
\hline & & GG & $16(0.102)$ & $4(0.052)$ & $\begin{array}{l}0.386 \\
(0.123- \\
1.216)\end{array}$ & $0.136 *$ \\
\hline & Dominant & AA & $85(0.541)$ & $55(0.714)$ & & \\
\hline & & $A G+G G$ & $72(0.459)$ & $22(0.286)$ & $\begin{array}{l}0.472 \\
(0.263- \\
0.848)\end{array}$ & 0.011 \\
\hline & Recessive & GG & $16(0.102)$ & $4(0.052)$ & & \\
\hline & & $A G+A A$ & $141(0.898)$ & $73(0.948)$ & $\begin{array}{l}2.071 \\
(0.668- \\
6.421)\end{array}$ & $0.225^{\star}$ \\
\hline & Additive & $A G$ & $56(0.357)$ & $18(0.234)$ & & \\
\hline & & $A A+G G$ & $101(0.643)$ & $59(0.766)$ & $\begin{array}{l}1.817 \\
(0.977- \\
3.380)\end{array}$ & 0.057 \\
\hline & Allele & $A$ & $226(0.720)$ & $128(0.831)$ & & \\
\hline & & G & $88(0.280)$ & $26(0.169)$ & $\begin{array}{l}0.522 \\
(0.320- \\
0.850)\end{array}$ & 0.008 \\
\hline \multirow[t]{5}{*}{ rs701848 } & Heterozygote & TT & $57(0.460)$ & $33(0.524)$ & & \\
\hline & & $\mathrm{TC}$ & $67(0.540)$ & $30(0.476)$ & $\begin{array}{l}0.773 \\
(0.421- \\
1.420)\end{array}$ & 0.407 \\
\hline & Homozygote & TT & $57(0.633)$ & $33(0.702)$ & & \\
\hline & & $\mathrm{CC}$ & $33(0.367)$ & $14(0.298)$ & $\begin{array}{l}0.733 \\
(0.343- \\
1.564)\end{array}$ & 0.421 \\
\hline & Dominant & TT & $57(0.363)$ & $33(0.429)$ & & \\
\hline
\end{tabular}

OR, Odds ratio; $\mathrm{Cl}$, Confidence interval.

*: Pass Fisher's exact test calculation.

$P$ value $<0.05$ was considered as significant. 


\begin{tabular}{|c|c|c|c|c|c|c|}
\hline \multirow[t]{8}{*}{ SNP } & Model & Allele/Genotype & Chemosensitive & Chemoresistant & $\begin{array}{l}\text { OR } \\
(95 \% \mathrm{Cl})\end{array}$ & $P$ \\
\hline & & $\mathrm{TC}+\mathrm{CC}$ & $100(0.637)$ & $44(0.571)$ & $\begin{array}{l}0.760 \\
(0.436- \\
1.326)\end{array}$ & 0.333 \\
\hline & Recessive & $\mathrm{CC}$ & $33(0.210)$ & $14(0.182)$ & & \\
\hline & & $\mathrm{TC}+\mathrm{TT}$ & $124(0.790)$ & $63(0.818)$ & $\begin{array}{l}1.198 \\
(0.598- \\
2.399)\end{array}$ & 0.611 \\
\hline & Additive & $\mathrm{TC}$ & $67(0.427)$ & $30(0.390)$ & & \\
\hline & & $\mathrm{TT}+\mathrm{CC}$ & $90(0.573)$ & $47(0.610)$ & $\begin{array}{l}1.166 \\
(0.668- \\
2.035)\end{array}$ & 0.588 \\
\hline & Allele & $\mathrm{T}$ & $181(0.576)$ & $96(0.623)$ & & \\
\hline & & C & $133(0.424)$ & $58(0.377)$ & $\begin{array}{l}0.822 \\
(0.554- \\
1.221)\end{array}$ & 0.332 \\
\hline \multirow[t]{11}{*}{ rs12402181 } & Heterozygote & GG & $60(0.403)$ & $33(0.485)$ & & \\
\hline & & GA & $89(0.597)$ & 35 (0.515) & $\begin{array}{l}0.715 \\
(0.401- \\
1.274)\end{array}$ & 0.254 \\
\hline & Homozygote & GG & $60(0.882)$ & $33(0.786)$ & & \\
\hline & & AA & $8(0.118)$ & $9(0.214)$ & $\begin{array}{l}2.045 \\
(0.721- \\
5.803)\end{array}$ & 0.173 \\
\hline & Dominant & $\mathrm{GG}$ & $60(0.382)$ & $33(0.429)$ & & \\
\hline & & $\mathrm{GA}+\mathrm{AA}$ & $97(0.618)$ & $44(0.571)$ & $\begin{array}{l}0.825 \\
(0.474- \\
1.436)\end{array}$ & 0.495 \\
\hline & Recessive & AA & $8(0.051)$ & $9(0.117)$ & & \\
\hline & & $G A+G G$ & 149 (0.949) & $68(0.883)$ & $\begin{array}{l}0.406 \\
(0.150- \\
1.097)\end{array}$ & 0.068 \\
\hline & Additive & GA & $89(0.567)$ & $35(0.455)$ & & \\
\hline & & $G G+A A$ & $68(0.433)$ & $42(0.545)$ & $\begin{array}{l}1.571 \\
(0.907- \\
2.718)\end{array}$ & 0.106 \\
\hline & Allele & G & $209(0.666)$ & $101(0.656)$ & & \\
\hline \multicolumn{7}{|c|}{ OR, Odds ratio; $\mathrm{Cl}$, Confidence interval. } \\
\hline \multicolumn{7}{|c|}{ *: Pass Fisher's exact test calculation. } \\
\hline ue $<0.0$ & considere & ignificant. & & & & \\
\hline
\end{tabular}




\begin{tabular}{|c|c|c|c|c|c|c|}
\hline SNP & Model & Allele/Genotype & Chemosensitive & Chemoresistant & $\begin{array}{l}\text { OR } \\
(95 \% \mathrm{Cl})\end{array}$ & $P$ \\
\hline & & A & $105(0.334)$ & $53(0.344)$ & $\begin{array}{l}1.045 \\
(0.695- \\
1.569)\end{array}$ & 0.834 \\
\hline \multirow[t]{12}{*}{ rs35770269 } & Heterozygote & AA & $54(0.425)$ & $34(0.500)$ & & \\
\hline & & AT & $73(0.575)$ & $34(0.500)$ & $\begin{array}{l}0.740 \\
(0.409- \\
1.336)\end{array}$ & 0.317 \\
\hline & Homozygote & $\mathrm{AA}$ & $54(0.643)$ & $34(0.791)$ & & \\
\hline & & TT & $30(0.357)$ & $9(0.209)$ & $\begin{array}{l}0.476 \\
(0.202- \\
1.126)\end{array}$ & 0.087 \\
\hline & Dominant & $\mathrm{AA}$ & $54(0.344)$ & $34(0.442)$ & & \\
\hline & & $\mathrm{AT}+\mathrm{TT}$ & $103(0.656)$ & $43(0.558)$ & $\begin{array}{l}0.663 \\
(0.380- \\
1.158)\end{array}$ & 0.148 \\
\hline & Recessive & TT & $30(0.191)$ & $9(0.117)$ & & \\
\hline & & $A T+A A$ & $127(0.809)$ & $68(0.883)$ & $\begin{array}{l}1.785 \\
(0.801- \\
3.976)\end{array}$ & 0.152 \\
\hline & Additive & AT & $73(0.465)$ & $34(0.442)$ & & \\
\hline & & $\mathrm{AA}+\mathrm{TT}$ & $84(0.535)$ & $43(0.558)$ & $\begin{array}{l}1.099 \\
(0.635- \\
1.902)\end{array}$ & 0.736 \\
\hline & Allele & A & $181(0.576)$ & $102(0.662)$ & & \\
\hline & & $\mathrm{T}$ & $133(0.424)$ & $52(0.338)$ & $\begin{array}{l}0.694 \\
(0.464- \\
1.037)\end{array}$ & 0.074 \\
\hline \multicolumn{7}{|c|}{ OR, Odds ratio; $\mathrm{Cl}$, Confidence interval. } \\
\hline \multicolumn{7}{|c|}{ *: Pass Fisher's exact test calculation. } \\
\hline \multicolumn{7}{|c|}{$P$ value $<0.05$ was considered as significant. } \\
\hline
\end{tabular}

\section{Logistic Regression Analysis}

The chemoresistance was used as the dependent variable, and related factors (sex, age, lymph node metastasis, rs786204926 genotype, etc.) were used as independent variables. Logistic regression analysis showed that age $(P=0.000)$ was risk factors for breast cancer chemoresistance. lymph node staging $(P=0.023)$ and rs786204926 AA/GG/AG genotype $(P=0.000)$ were protective factors for breast cancer chemoresistance (Figure 1D). 


\section{Linkage Disequilibrium (Ld) And Haplotype Analysis}

SHEsis software was used to analyse the LD of the two polymorphisms of PTEN. Complete LD was detected in the polymorphisms of rs701848 and $r s 786204926\left(r^{2}=0.222, D^{\prime}=1.000\right)$ (Figure 2A, 2B and 2C). At the same time, haplotype analysis was performed, the chemosensitive and chemoresistant groups with haplotype estimated frequency less than $3 \%$ were excluded from further analysis. We found that TA, TG haplotypes (rs701848, rs786204926) were related to chemosensitivity. Carrying TA might increase the risk of chemoresistance. Carrying TG might decrease the risk of chemoresistance. Other haplotypes were not significantly different between the chemosensitive and chemoresistant groups (Figure 2D).

\section{rs786204926 affects a new PTEN isoform expression association with drug sensitivity}

According to The cBioPortal for Cancer Genomics (http://cbioportal.org) database analysis of samples with mutation data in invasive breast cancer (TCGA, Firehose Legacy) [33, 34], PTEN had mutations in $9 \%$ of patients (Figure 3A), and mutations in PTEN are associated with overall survival (Figure 3C). In order to study the correlation between the PTEN mutant genome and epirubicin drug sensitivity in breast cancer, we used GDSC online software for analysis. The results showed that PTEN mutant genome would increase the sensitivity of epirubicin drug in breast cancer (Figure 3C). The database had reported that there are two splice sites (X70_splice, X212_splice) on the PTEN gene. We predicted that the rs786204926 is also a splice site (Figure 3D). Mutations at the splicing site might affect AS of genes, and these effects had been detected by Alamut Visual v.2.15 and HSF. HSF predicted whether the rs786204926A $>G$ mutation affected AS. The prediction results showed that rs786204926 is a splice acceptor site, when carrying $\mathrm{G}$ allele, it will destroy the wild-type acceptor site and affect splicing (Supplementary Table 4). Further using Alamut Visual v.2.14 showed that the rs786204926A>G mutation destroyed the acceptor site and created a new acceptor site. It also showed the changes between the exon splicing enhancers (ESE) after mutation, the results showed that the ESE binding ability is weakened after mutation (Figure $3 \mathrm{E}$ ).

\section{Higher levels of new isoforms of PTEN in chemosensitive samples of breast cancer}

We randomly selected 6 breast cancer tissues after chemotherapy (2 GG types, 2 AG types, and 2 AA types). Perform RT-PCR amplification on the sample, and agarose gel electrophoresis on the products and sequence verification, the results showed that PTEN wild type had no difference among alleles (Figure 4). In PTEN mutant isoforms, $A G$ and $A A$ genotypes are statistically significant compared with $G G$ alleles $(P<0.05)$. The results show that rs786204926 affects the production of PTEN isoforms, and the levels of new PTEN subtypes are higher in breast cancer chemosensitive samples.

We randomly selected 9 breast cancer tissues after chemotherapy (3 GG types, 3 AG types, and 3 AA types). WB results showed that in PTEN wild type and mutant type, AG and AA genotypes were statistically significant compared with $\mathrm{GG}$ alleles $(P<0.05)$. The AG and AA genotype in SRP40 and ASF/SF2 were statistically significant compared with the GG allele $(P<0.05)$ (Figure 5). The results showed that SNP and splicing factor related to breast cancer chemosensitivity, and the levels of PTEN-W and PTEN-M are higher in breast cancer chemosensitive samples.

The difference response of wild and mutant PTEN isoforms to PI3K drug-resistance signalling pathway 
According to the predicted amino acid sequence, we used Pymol2.3.0 for homology modeling and predicted the changes in the protein structure after mutation (Figure 6A). The results showed the spatial structure of the protein was changed after gene mutation. In wild type, the amino acids D324, Y177, Y176, Q149, K183, and R189 of INS form hydrogen bonds with R46, E45, R48, E7, and Q91 of PTEN respectively; the amino acids 192, F44, 195, Y42, K41, D43, M89, 194, 19, L29, and R49 have hydrophobic interactions with the amino acids L318, F278, I280, P281, F279, P283, Y180, D187, E284, L186, L181, Y188, N184, K147 of PTEN respectively, and constitute a hydrophobic surface. The above residues may It constitutes the active surface for the interaction between the two. In the mutant, amino acids N24, K26, K53, R28, R48, E45, and Q91 of INS form hydrogen bonds with mutant K295, V296, E294, E291, Y182, Y183, and D193 respectively; amino acids L11, E76, F98, E96, P75 of INS, K27, F44, Y42, D43, G47, I9, R49, S21, I92, P22, L29, L23 and mutant C310, I312, F285, I286, G288, L324, Q313, Y186, P289, P287, E290, N190, F284, S293, K153, T292, L192, R195, D307, G299, Q297, Y182 have a hydrophobic effect and constitute a hydrophobic surface. The above residues may constitute an active surface for the interaction of the two. The results of protein docking showed that hydrogen bonding and hydrophobic interaction increased after PTEN mutation, mediating the interaction between PTEN and PIP3, making PIP3 more easily dephosphorylated into PIP2. Compared with PTEN-W, PTEN-M is more prone to phosphorylation, leading to chemosensitivity (Figure 6B). WB results showed that $A G$ and AA genotypes were statistically significant compared with GG alleles in P-PI3K $(P<0.05)$ (Figure 6C). It further confirmed that PTEN-W/M leads to chemosensitivity through the PI3K-AKT pathway signaling pathway.

\section{Discussion}

PTEN is the first reported tumour suppressor gene with phosphatase activity, which plays a vital role in cell apoptosis, cell cycle arrest and cell migration, and is closely related to the occurrence and development of a variety of human malignant tumours[35-37]. Mutations or deletions of PTEN in a variety of malignant tumours, resulting in weakened or lost tumour suppressor function[15]. PTEN has a high deletion or mutation rate in breast cancer, and its loss of function is closely related to the malignant transformation of breast cancer. Liang $\mathrm{H}$ et al. found that the PTEN gene can produce new isoforms PTEN $\beta$, PTEN $\beta$ protein specifically locates in the nucleolus, binds to nucleolin and regulates its phosphorylation level, thereby regulating rDNA transcription and ribosome production, and inhibiting cell proliferation[27]. Agrawal $S$ et al. found that there are new isoforms in sporadic breast cancer tissues. They are produced a short-lived structure PTEN by different splicing methods of PTEN introns 3 and 5, and its phosphatase activity is also limited. The short-lived structure PTEN plays an important role in the occurrence and development of sporadic breast cancer[26]. In addition, many studies have reported that PTEN gene plays an important role in multi-drug resistance in cancers, PTEN can specifically dephosphorylate PIP3 in the cell membrane, thereby antagonizing the PI3K/AKT signaling pathway, leading to the development of drug resistance[38]. Previously, people thought that the high expression of PTEN was related to chemosensitivity, but people did not notice the expression of PTEN isoforms. In our research, we discovered a new PTEN isoform, which is closely related to chemosensitivity in breast cancer.

Previous studies have shown that SNP of PTEN might be a candidate pharmacogenomic factor to assess the susceptibility of breast cancer and response and prognosis prediction for chemotherapy in breast cancer[39]. Therefore, PTEN gene polymorphism was related to chemoresistance of breast cancer. In recent years, it has been found that PTEN gene polymorphism and chemoresistance are different in breast cancer. However, the potential association between rs786204926, rs701848, rs12402181, rs35770269 and chemoresistance in breast 
cancer has not been reported. In our research, we selected rs786204926, rs701848, rs12402181, rs35770269 to study the potential association between gene polymorphism and chemoresistance in breast cancer. Our research showed that rs786204926 of PTEN was closely related to breast cancer chemoresistance, and carrying the G allele or AG genotype will increase the risk of chemosensitive in breast cancer. Previous studies have confirmed that rs701848, rs12402181, and rs35770269 are related to drug resistance[39-41], but we have not found any correlation with breast cancer chemoresistance. It might be the association between genetic polymorphisms and breast cancer varies greatly among different races, indicating that different genetic backgrounds have different mutation frequencies[42]. In addition, studies have shown that genetic SNP might change the response to drugs, and there are significant differences between different races[43]. This indicates that mutations have different therapeutic effects on people with different genetic backgrounds. China has a vast territory and a large population. Different regions have different eating habits, cultural backgrounds, living environments, and genetic backgrounds. Our samples mainly collected patients from Northwest China. All samples came from patients in the hospital, so we analysed patients who did not meet the HW equilibrium state. This study is the first time to detect and analyse the PTEN gene polymorphism of rs786204926 in Northwest China. It provides important theoretical data for establishing a database of PTEN gene polymorphism in Northwest China and promoting pharmacogenomics research to achieve personalized medicine.

Compared with previous studies related to chemoresistance, our research not only find new SNP related to chemoresistance, but also used software to predict the correlation between rs786204926 and AS. Up to $50 \%$ of all mutations leading to genetic diseases result in abnormal splicing[44]. It has been found that PTEN splicing aberrations might be caused by genetic mutations at the junction of the splicing sites and deep in the introns[45]. The function of splice sites is to "signal" the assembling snRNAs and auxiliary splicing factors to recognize the "staging area" in order to initiate the assembly of the spliceosome eventually leading to the excision of intron and joining of exons to yield a mature mRNA[46]. This is one of the important mechanisms of AS involved in the occurrence and development of various diseases. When an $A>G$ mutation occurs at this site, it will destroy the wild-type acceptor site to create a new acceptor site and affect AS. After mutation, there are 18 bases from premRNA intron 4 will be retained on the mature mRNA, and the exon splicing enhancer (ESE) binding ability will also change, which might eventually cause the mutant protein to have 6 amino acids more than the wild type. In the structure of PTEN protein, the N-terminal phosphatase domain composed of N-terminal amino acids 1-185 is closely related to its phosphatase function[47]. The 6 amino acids produced by the mutant are exactly in this domain, which will cause the protein structure to change. After mutation, we found that there are varying degrees of protein structure changes in the amino acids. PTEN is a tumour suppressor gene with phosphatase activity[36]. On the cell membrane, PTEN mediates the conversion of 3,4,5-phosphatidylinositol triphosphate (PIP3) to PIP2, and inhibits the PI3K/Akt pathway to arrest the cell cycle In the G1 phase,lead to the development of drug resistance[48-50]. When rs786204926A $>\mathrm{G}$ is mutated, AS may cause changes in mRNA and protein, resulting in a new isoform of PTEN-M, which will eventually lead to the reduction or loss of the function of PTEN phosphatase. Loss of PTEN function will lose its negative regulatory effect on PI3K/Akt, Akt will be continuously activated, the cell cycle will be accelerated, and cell growth and proliferation will be accelerated, reducing the risk of breast cancer chemoresistance. Previously, people thought that PTEN was related to chemosensitivity, but people did not notice the expression of PTEN isoforms. In our research, we have discovered a new PTEN-W isoform in breast cancer. In the past, when studying PTEN, whether it was RT-PCR or WB, the sum of the wild and isoforms of PTEN was regarded as the expression level of PTEN. In our research, we have done a more detailed study, and the results suggest that we should pay attention to the respective expression levels of PTEN-W and 
PTEN-M isoforms. We analysed the collected clinical samples and found the correlation between rs786204926 polymorphism and chemosensitivity in breast cancer, and the $\mathrm{G}$ allele was associated with chemosensitivity in breast cancer. Later, we performed transcript and protein level verification. Carrying $\mathrm{G}$ allele is easier to produce PTEN-W in chemosensitivity patients. There is no difference in the transcription level of PTEN-W, but there is a significant difference in the protein level. PTEN-M has no difference in transcription and protein levels. Therefore, we found that PTEN-W is not related to chemosensitivity, PTEN-M is related to chemosensitivity, and the higher expression of PTEN-M, the more sensitive it is. At the same time, through software analysis, we found that PTEN$M$ has a stronger binding ability with PIP3 and is easier to exert its dephosphorylation effect, thereby inhibiting the PI3K-AKT pathway and leading to chemosensitivity. Therefore, we suspect that chemosensitivity of breast cancer patients is mainly caused by the AS of PTEN gene rs786204926 polymorphism (Figure 7).

Previous studies mainly collected clinical information and blood samples, test results, and statistical analysis to obtain the association between gene polymorphism and breast cancer chemoresistance. However, the mechanism of chemoresistance has not been further studied. Here, we have not only conducted association studies, but also predicted the function of SNPs in chemotherapy resistance-related genes by silico analysis, and further experiments also verify this possibility. We speculate that the mechanism of breast cancer chemosensitivity might be caused by a change in AS caused by rs786204926 of PTEN gene.

\section{Conclusions}

In conclusion, we hypothesize that the mechanism of breast cancer chemosensitivity might be caused by a change in AS caused by the rs786204926 of the PTEN gene. Our work not only provides theoretical guidance for the individualized treatment of clinical breast cancer patients in the Chinese population, but also provides new ideas for the mechanism of breast cancer chemoresistance.

\section{Abbreviations}

SNP: Single nucleotide polymorphism; Ptdlns-3,4,5-P3: phosphatidylinositol (3,4,5)-triphosphate; AS: Alternative splicing; ESE: Exon splicing enhancer; HW: Hardy-Weinberg; LD: Linkage disequilibrium; ER: Estrogen receptor; PR: Progesterone receptor; C-erbB-2: human epidermal growth factor receptor 2

\section{Declarations}

\section{Ethics approval and consent to participate}

The study was approved by the ethics committee of Lanzhou University School of Basic Medicine and the written informed consent was obtained from all patients.

\section{Consent for publication}

All authors have agreed on the contents of the manuscript.

\section{Availability of data and material}

All the data and materials are available. 


\section{Competing Interests}

The authors have declared that no competing interest exists.

\section{Funding}

This work was supported by the national Key R\&D project of the Chinese Ministry of Science and Technology (2018YFE0205100), the Gansu Province Science and Technology Innovation Service Platform Construction Project (18JR2TA024), the Key Program of the National Natural Science Foundation of China (U1632270), the National Natural Science Foundation of China (11675234), and the Science and Technology Plan Project of Lanzhou (2019-4-7).

\section{Authors' contributions}

Study concept and design: Cuixia Di and Xiaodong Xie. Drafting of the manuscript: Jing Wang. Critical revision of the manuscript for important intellectual content: ShaSha Zhang, Jiaxin Zhang, Zhongliang Zhang, Qinglong Ma, Wenkang Fu, Xiaohua Chen, Dapeng Zhao, Meie Zhao, Chunwei Wang. All authors read and approved the final manuscript.

\section{Acknowledgements}

We give our sincere gratitude to the colleagues for their valuable suggestions and technical assistance for this study.

\section{References}

1. Siegel RL, Miller KD, Jemal A. Cancer statistics. 2018. CA: a cancer journal for clinicians. 2018;68(1):7-30.

2. Carioli G, Malvezzi M, Rodriguez T, Bertuccio P, Negri E, La Vecchia C. Trends and predictions to 2020 in breast cancer mortality: Americas and Australasia. Breast (Edinburgh, Scotland). 2018;37:163-9.

3. Chen W, Zheng R, Baade PD, Zhang S, Zeng H, Bray F, et al. Cancer statistics in China, 2015. Cancer J Clin. 2016;66(2):115-32.

4. Holohan C, Van Schaeybroeck S, Longley DB, Johnston PG. Cancer drug resistance: an evolving paradigm. Nature reviews Cancer. 2013;13(10):714-26.

5. Crystal AS, Shaw AT, Sequist LV, Friboulet L, Niederst MJ, Lockerman EL, et al. Patient-derived models of acquired resistance can identify effective drug combinations for cancer. Science. 2014;346(6216):1480-6.

6. Pan X, Hong X, Lai J, Cheng L, Cheng Y, Yao M, et al. Exosomal MicroRNA-221-3p Confers Adriamycin Resistance in Breast Cancer Cells by Targeting PIK3R1. Frontiers in oncology. 2020;10:441.

7. Li M, Wu XM, Gao J, Yang F, Zhang CL, Ke K, et al. Mutations in the P10 region of procaspase-8 lead to chemotherapy resistance in acute myeloid leukemia by impairing procaspase-8 dimerization. Cell death disease. 2018;9(5):516.

8. Rosell R, Felip E. Predicting response to paclitaxel/carboplatin-based therapy in non-small cell lung cancer. Seminars in oncology. 2001;28(4 Suppl 14):37-44.

9. Steelman LS, Navolanic PM, Sokolosky ML, Taylor JR, Lehmann BD, Chappell WH, et al. Suppression of PTEN function increases breast cancer chemotherapeutic drug resistance while conferring sensitivity to 
mTOR inhibitors. Oncogene. 2008;27(29):4086-95.

10. Liu Y, Yang EJ, Zhang B, Miao Z, Wu C, Lyu J, et al. PTEN deficiency confers colorectal cancer cell resistance to dual inhibitors of FLT3 and aurora kinase A. Cancer letters. 2018;436:28-37.

11. Cheng F, Eng C. PTEN Mutations Trigger Resistance to Immunotherapy. Trends Mol Med. 2019;25(6):461-3.

12. Fletcher JI, Williams RT, Henderson MJ, Norris MD, Haber M. ABC transporters as mediators of drug resistance and contributors to cancer cell biology. Drug resistance updates: reviews commentaries in antimicrobial anticancer chemotherapy. 2016;26:1-9.

13. Pajic M, lyer JK, Kersbergen A, van der Burg E, Nygren AO, Jonkers J, et al. Moderate increase in Mdr1a/1b expression causes in vivo resistance to doxorubicin in a mouse model for hereditary breast cancer. Cancer research. 2009;69(16):6396-404.

14. Wein L, Loi S. Mechanisms of resistance of chemotherapy in early-stage triple negative breast cancer (TNBC). Breast. 2017;34(Suppl 1):27-s30.

15. Simpson L, Parsons R. PTEN: life as a tumor suppressor. Experimental cell research. 2001;264(1):29-41.

16. Wang ZX, Lu BB, Wang H, Cheng ZX, Yin YM. MicroRNA-21 modulates chemosensitivity of breast cancer cells to doxorubicin by targeting PTEN. Arch Med Res. 2011;42(4):281-90.

17. Liu L, Meng T, Zheng X, Liu Y, Hao R, Yan Y, et al. Transgelin 2 Promotes Paclitaxel Resistance, Migration, and Invasion of Breast Cancer by Directly Interacting with PTEN and Activating PI3K/Akt/GSK-3 $\beta$ Pathway. Mol Cancer Ther. 2019;18(12):2457-68.

18. Gao C, Yuan X, Jiang Z, Gan D, Ding L, Sun Y, et al. Regulation of AKT phosphorylation by GSK3 $\beta$ and PTEN to control chemoresistance in breast cancer. Breast cancer research treatment. 2019;176(2):291-301.

19. Gao Y, Li X, Zeng C, Liu C, Hao Q, Li W, et al. CD63(+) Cancer-Associated Fibroblasts Confer Tamoxifen Resistance to Breast Cancer Cells through Exosomal miR-22. Advanced science (Weinheim, BadenWurttemberg, Germany). 2020;7(21):2002518.

20. Gong C, Yao Y, Wang Y, Liu B, Wu W, Chen J, et al. Up-regulation of miR-21 mediates resistance to trastuzumab therapy for breast cancer. J Biol Chem. 2011;286(21):19127-37.

21. Yehia L, Keel E, Eng C. The Clinical Spectrum of PTEN Mutations. Annual review of medicine. 2020;71:10316.

22. Xiao F, Zhang P, Wang Y, Tian Y, James M, Huang CC, et al. Single-nucleotide polymorphism rs13426236 contributes to an increased prostate cancer risk via regulating MLPH splicing variant 4. Molecular carcinogenesis. 2020;59(1):45-55.

23. Fairbrother WG, Holste D, Burge CB, Sharp PA. Single nucleotide polymorphism-based validation of exonic splicing enhancers. PLoS Biol. 2004;2(9):E268.

24. Knudsen KE, Diehl JA, Haiman CA, Knudsen ES. Cyclin D1: polymorphism, aberrant splicing and cancer risk. Oncogene. 2006;25(11):1620-8.

25. Di C, Syafrizayanti, Zhang Q, Chen Y, Wang Y, Zhang X, et al. Function, clinical application, and strategies of Pre-mRNA splicing in cancer. Cell Death Differ. 2019;26(7):1181-94.

26. Agrawal S, Eng C. Differential expression of novel naturally occurring splice variants of PTEN and their functional consequences in Cowden syndrome and sporadic breast cancer. Human molecular genetics. 2006;15(5):777-87. 
27. Liang $H$, Chen $X$, Yin Q, Ruan D, Zhao X, Zhang C, et al. PTEN $\beta$ is an alternatively translated isoform of PTEN that regulates rDNA transcription. Nat Commun. 2017;8:14771.

28. Wang C, Yang D, Zhang X, Zhang X, Yang L, Wang P, et al. Association of PTEN Gene SNPs rs2299939 With PFS in Patients With Small Cell Lung Cancer Treated With Early Radiotherapy. Frontiers in genetics. 2020;11:298.

29. Wang F, Diao XY, Zhang X, Shao Q, Feng YF, An X, et al. Identification of genetic alterations associated with primary resistance to EGFR-TKIs in advanced non-small-cell lung cancer patients with EGFR sensitive mutations. Cancer communications (London England). 2019;39(1):7.

30. Eisenhauer EA, Therasse P, Bogaerts J, Schwartz LH, Sargent D, Ford R, et al. New response evaluation criteria in solid tumours: revised RECIST guideline (version 1.1). European journal of cancer (Oxford, England: 1990). 2009;45(2):228-47.

31. Yang W, Soares J, Greninger P, Edelman EJ, Lightfoot H, Forbes S, et al. Genomics of Drug Sensitivity in Cancer (GDSC): a resource for therapeutic biomarker discovery in cancer cells. Nucleic acids research. 2013;41(Database issue):D955-61.

32. Lee JO, Yang H, Georgescu MM, Di Cristofano A, Maehama T, Shi Y, et al. Crystal structure of the PTEN tumor suppressor: implications for its phosphoinositide phosphatase activity and membrane association. Cell. 1999;99(3):323-34.

33. Gao J, Aksoy BA, Dogrusoz U, Dresdner G, Gross B, Sumer SO, et al. Integrative analysis of complex cancer genomics and clinical profiles using the cBioPortal. Sci Signal. 2013;6(269):pl1.

34. Cerami E, Gao J, Dogrusoz U, Gross BE, Sumer SO, Aksoy BA, et al. The cBio cancer genomics portal: an open platform for exploring multidimensional cancer genomics data. Cancer discovery. 2012;2(5):401-4.

35. Cantley LC, Neel BG. New insights into tumor suppression: PTEN suppresses tumor formation by restraining the phosphoinositide 3-kinase/AKT pathway. Proc Natl Acad Sci USA. 1999;96(8):4240-5.

36. Worby CA, Dixon JE. PTEN Annual review of biochemistry. 2014;83:641-69.

37. Milella M, Falcone I, Conciatori F, Cesta Incani U, Del Curatolo A, Inzerilli N, et al. PTEN: Multiple Functions in Human Malignant Tumors. Frontiers in oncology. 2015;5:24.

38. Wu H, Wang K, Liu W, Hao Q. PTEN overexpression improves cisplatin-resistance of human ovarian cancer cells through upregulating KRT10 expression. Biochem Biophys Res Commun. 2014;444(2):141-6.

39. Li X, Zhang R, Liu Z, Li S, Xu H. The genetic variants in the PTEN/PI3K/AKT pathway predict susceptibility and $C E(A) F$ chemotherapy response to breast cancer and clinical outcomes. Oncotarget. 2017;8(12):2025265.

40. Mao Y, Zou C, Meng F, Kong J, Wang W, Hua D. The SNPs in pre-miRNA are related to the response of capecitabine-based therapy in advanced colon cancer patients. Oncotarget. 2018;9(6):6793-9.

41. Gutierrez-Camino Á, Umerez M, Martin-Guerrero I, García de Andoin N, Santos B, Sastre A, et al. Mirpharmacogenetics of Vincristine and peripheral neurotoxicity in childhood B-cell acute lymphoblastic leukemia. Pharmacogenomics J. 2018;18(6):704-12.

42. Cai Q, Wen W, Qu S, Li G, Egan KM, Chen K, et al. Replication and functional genomic analyses of the breast cancer susceptibility locus at 6q25.1 generalize its importance in women of chinese, Japanese, and European ancestry. Cancer research. 2011;71(4):1344-55. 
43. Sandanaraj E, Lal S, Selvarajan V, Ooi LL, Wong ZW, Wong NS, et al. PXR pharmacogenetics: association of haplotypes with hepatic CYP3A4 and ABCB1 messenger RNA expression and doxorubicin clearance in Asian breast cancer patients. Clinical cancer research: an official journal of the American Association for Cancer Research. 2008;14(21):7116-26.

44. Cartegni L, Chew SL, Krainer AR. Listening to silence and understanding nonsense: exonic mutations that affect splicing. Nature reviews Genetics. 2002;3(4):285-98.

45. Agrawal S, Pilarski R, Eng C. Different splicing defects lead to differential effects downstream of the lipid and protein phosphatase activities of PTEN. Human molecular genetics. 2005;14(16):2459-68.

46. Shukla GC, Singh J. Mutations of RNA splicing factors in hematological malignancies. Cancer letters. 2017;409:1-8.

47. Hopkins BD, Hodakoski C, Barrows D, Mense SM, Parsons RE. PTEN function: the long and the short of it. Trends Biochem Sci. 2014;39(4):183-90.

48. Carnero A, Paramio JM. The PTEN/PI3K/AKT Pathway in vivo. Cancer Mouse Models Frontiers in oncology. 2014;4:252.

49. Furnari FB, Huang HJ, Cavenee WK. The phosphoinositol phosphatase activity of PTEN mediates a serumsensitive 11 growth arrest in glioma cells. Cancer research. 1998;58(22):5002-8.

50. Jin $\mathrm{H}$, Sun $Y$, Wang S, Cheng $X$. Matrine activates PTEN to induce growth inhibition and apoptosis in V600EBRAF harboring melanoma cells. Int J Mol Sci. 2013;14(8):16040-57.

\section{Figures}


A
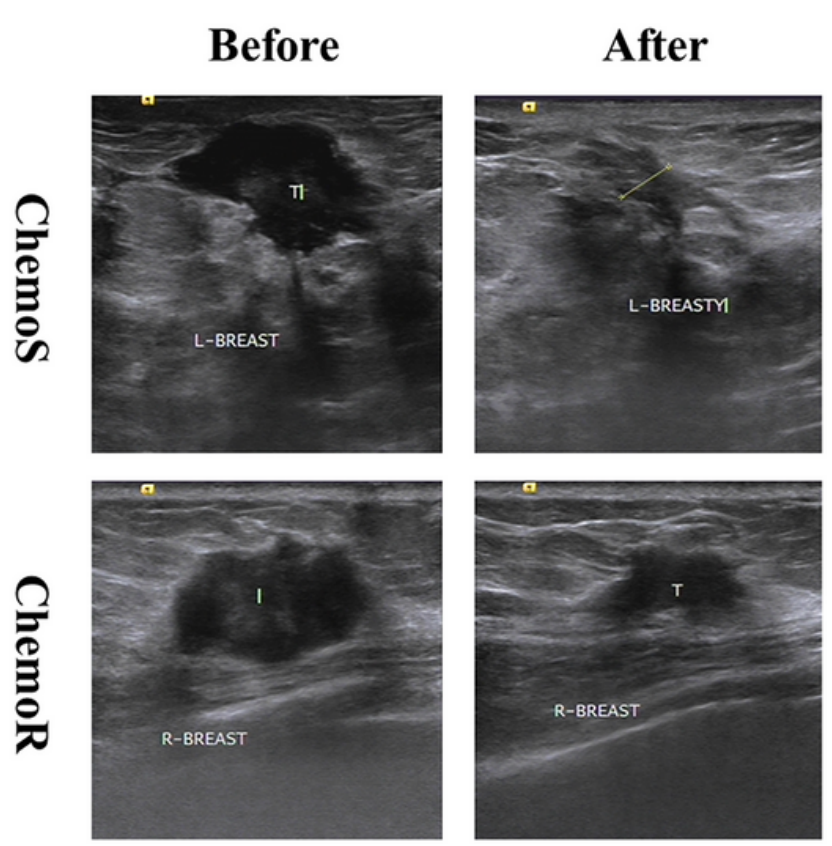

B
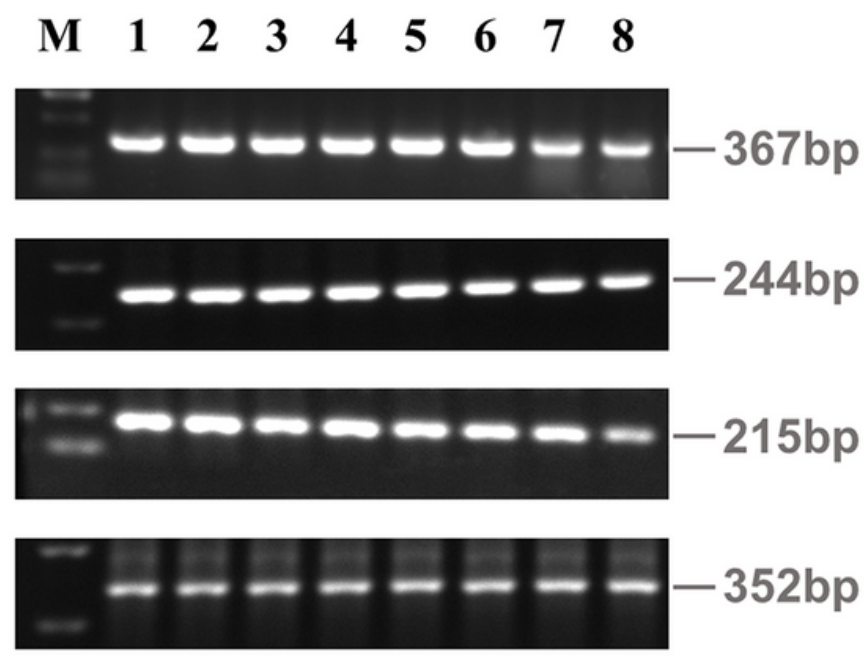

C

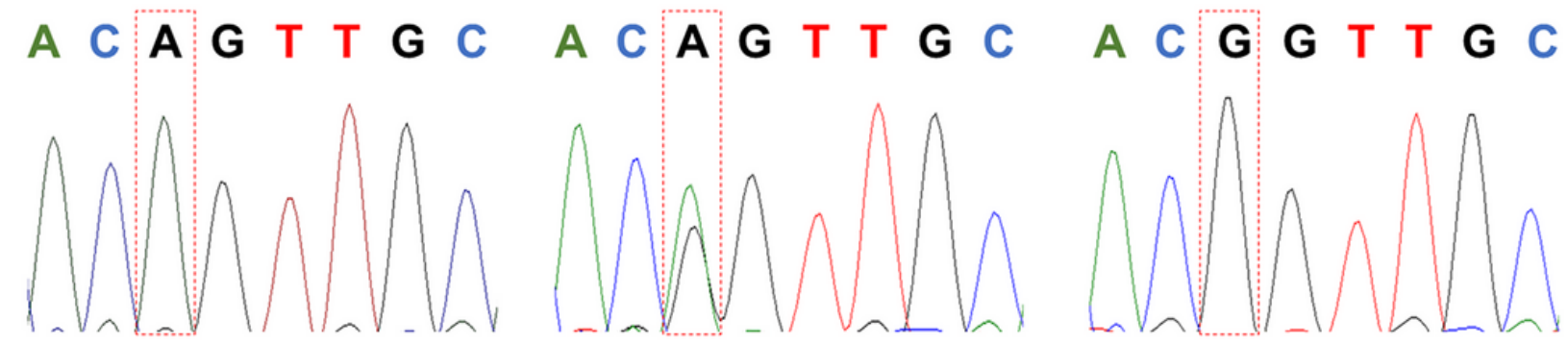

D

\begin{tabular}{cccccc}
\hline & B & S.E. & $\boldsymbol{P}$ & $\operatorname{Exp}(\mathrm{B})$ & $\mathbf{9 5 \%}$ Cl for $\operatorname{Exp}(\mathrm{B})$ \\
\hline rs786204926AA/AG & -2.755 & 0.564 & $\mathbf{0 . 0 0 0}$ & 0.064 & $0.021-0.192$ \\
rs786204926AA/GG & -3.774 & 0.950 & $\mathbf{0 . 0 0 0}$ & 0.023 & $0.004-0.148$ \\
Age & 0.318 & 0.063 & $\mathbf{0 . 0 0 0}$ & 1.375 & $1.216-1.555$ \\
Lymph node staging & -1.121 & 0.494 & $\mathbf{0 . 0 2 3}$ & 0.326 & $0.124-0.859$ \\
\hline
\end{tabular}

Figure 1

The relationship between PTEN polymorphism and chemosensitivity. (A) The imagological examination data of breast cancer patients. According to the tumour size before and after chemotherapy, it is divided into chemosensitivity and chemoresistance. (B) PCR electropherograms of four SNPs in partial DNA samples, followed by rs786204926, rs701848, rs12402181, rs35770269. (C) Sequence verification of rs786204926 polymorphism: GG-wild type homozygous, AG-heterozygote, AA-SNP homozygous. The red box is the position of the rs786204926 polymorphism base mutation. (D) Logistic regression analysis of the relationship between polymorphism and chemoresistance related factors. 
A

\begin{tabular}{cccc}
\hline$D^{\prime}$ & rs786204926 & $r^{2}$ & rs786204926 \\
\hline rs701848 & 1.000 & rs701848 & 0.222 \\
\hline
\end{tabular}

B

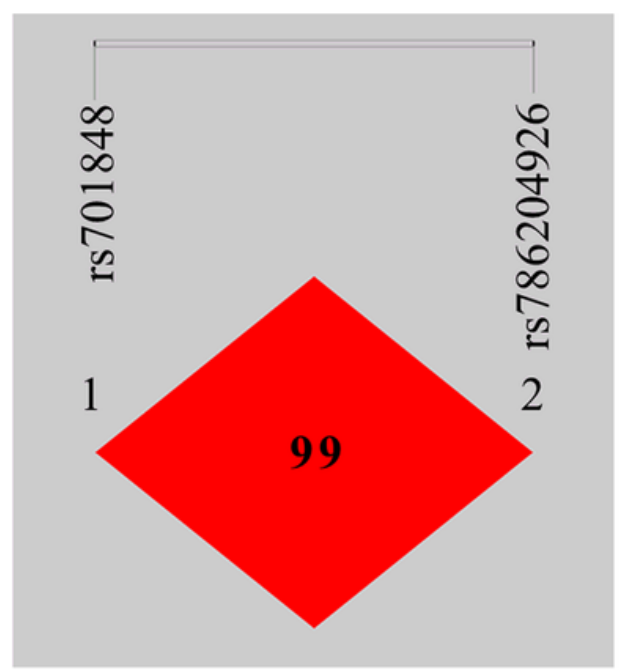

C

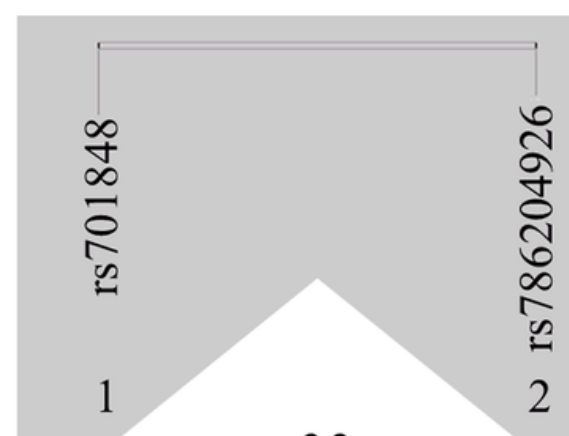

22

Frequency $\mathbf{n}(\%)$

Haplotype

Chemos

ChemoR

OR $(95 \% \mathrm{Cl})$

$\boldsymbol{P}$

CA

$58.00(0.377)$

133.00(0.424)

$0.822(0.554 \sim 1.221) \quad 0.331$

TA

70.00(0.455)

93.00(0.296)

1.980(1.329 2.952) $\mathbf{0 . 0 0 1}$

TG

26.00(0.169)

88.00(0.280)

0.522(0.320 0.850)

0.008

Figure 2

Linkage disequilibrium and haplotype analysis for two polymorphisms of the PTEN gene. (A) (B) (C) SHEsis software analyses the LD relationship of two polymorphisms of PTEN, and uses D' and r2 to measure the LD relationship between the two SNPs. (D) Results of haplotype analysis of two PTEN polymorphisms in chemosensitive and chemoresistant groups. 
PTEN 9\% |

Amplification

Deletion

Truncating

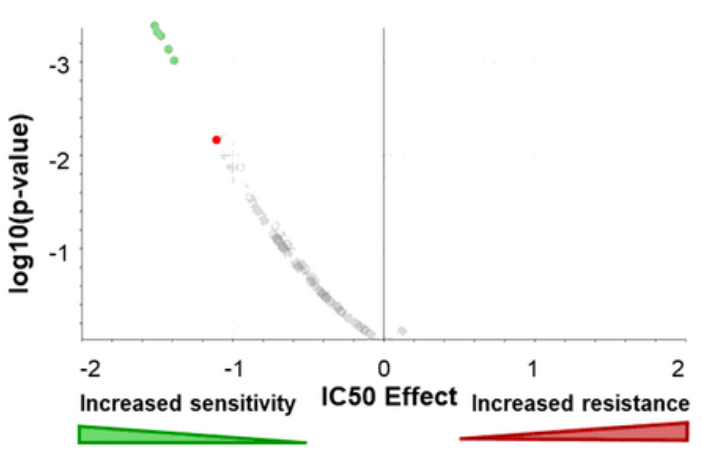

D

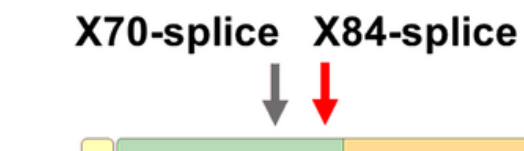

C

Mutation

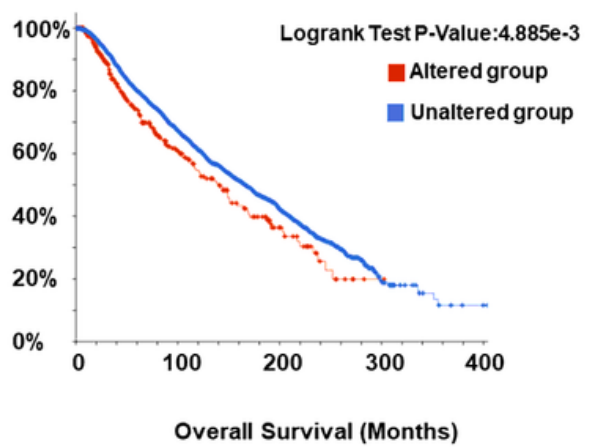

X212-splice

$\downarrow$

Phospholipid binding

Regulatory

PDZ-BD

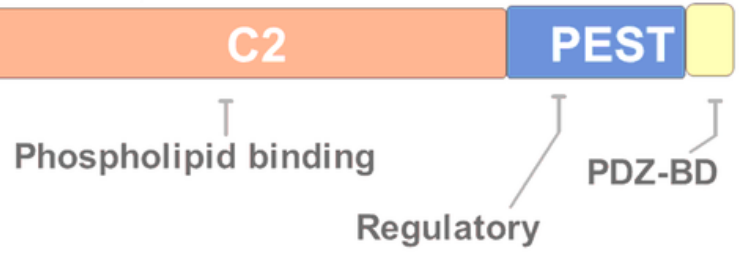

E

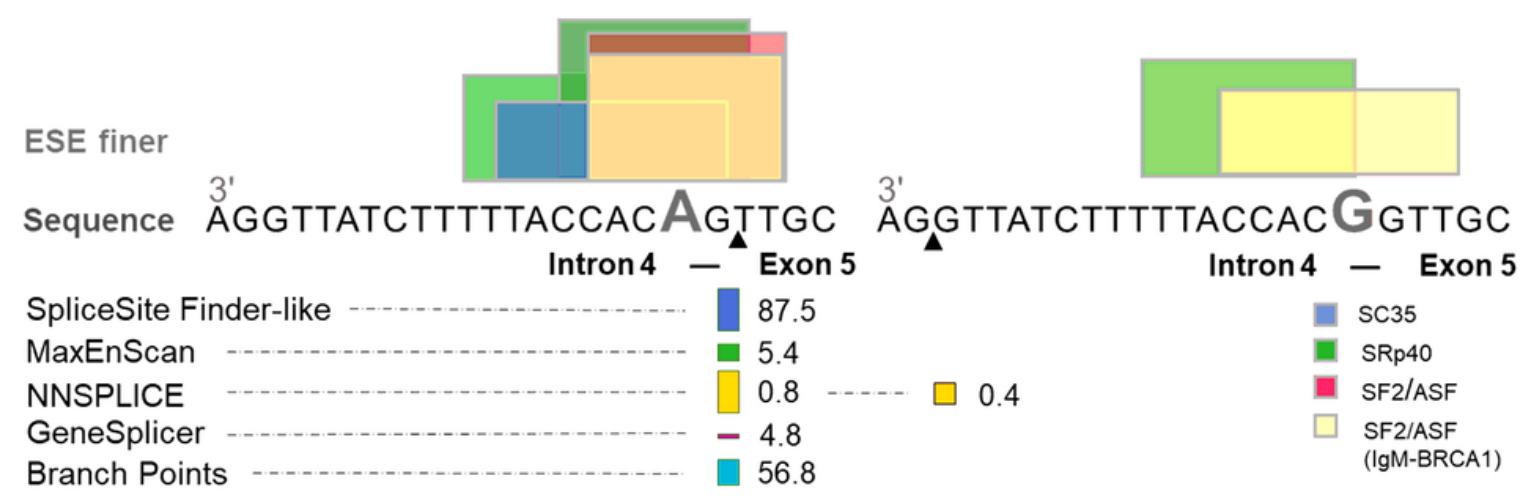

Figure 3

rs786204926 affects a new PTEN isoform expression association with drug sensitivity. (A) The cBioPortal for Cancer Genomics database analysis of samples with mutation data in invasive breast cancer, PTEN had mutations in $9 \%$ of patients (B) The association of PTEN mutation genome and chemotherapeutic drug sensitivity in breast cancer. Each circle represents an association between a genomic marker and drug sensitivity analysed using ANOVA. The red circle represents the association between epirubicin sensitivity and the PTEN mutant genome. (C) The relationship between PTEN mutant genome and overall survival in breast cancer. (D) Schematic diagram of the PTEN domain. The red arrow indicates the newly discovered splice site in PTEN, and the gray indicates the splice site that has been found in the database. (E) Using Alamut Visual to analyze the 
effect of rs786204926 on alternative splicing of the PTEN gene. rs786204926A>G destroys the original 3' splice site and creates a new 3' splice site. The triangle represents the new splice site. The figure also shows the changes of splicing enhancers after rs786204926A>G mutation.

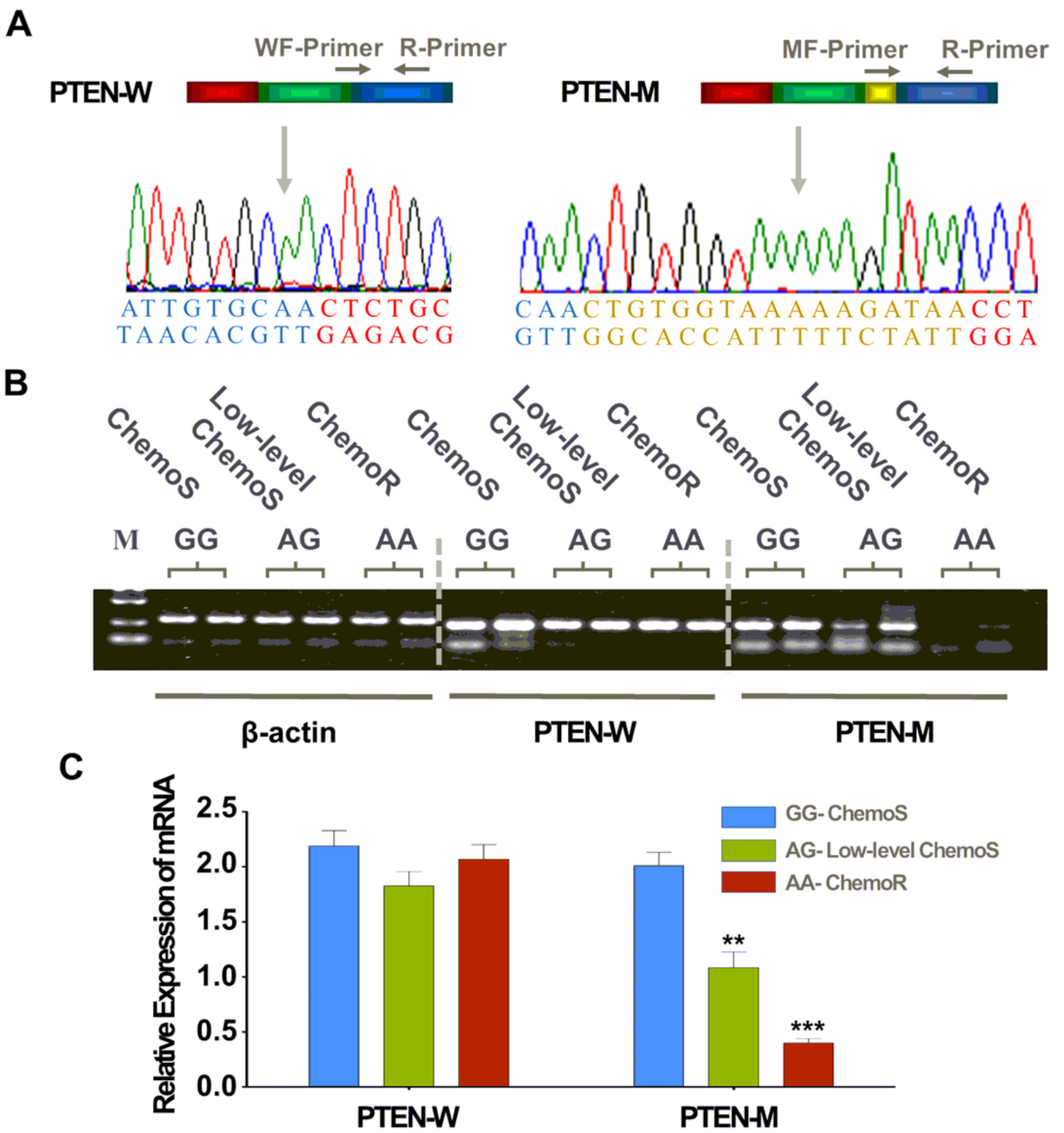

Figure 4

Relative mRNA level of new isoforms of PTEN in samples of breast cancer. (A) Schematic diagram of primers and sequencing verification diagram for RT-PCR. Yellow is the retained intron fragments in the mRNA. (B) After the sample is amplified by RT-PCR, it is subjected to $1 \%$ agarose gel electrophoresis, and the electrophoresis bands of PTEN wild type and mutant type. According to the different genotypes (GG, $A G, A A)$ of the samples, 
they are divided into chemosensitive, Low-level chemosensitive, chemoresistant groups. (C) Statistical analysis chart of gray value of PTEN wild and mutant isoforms.

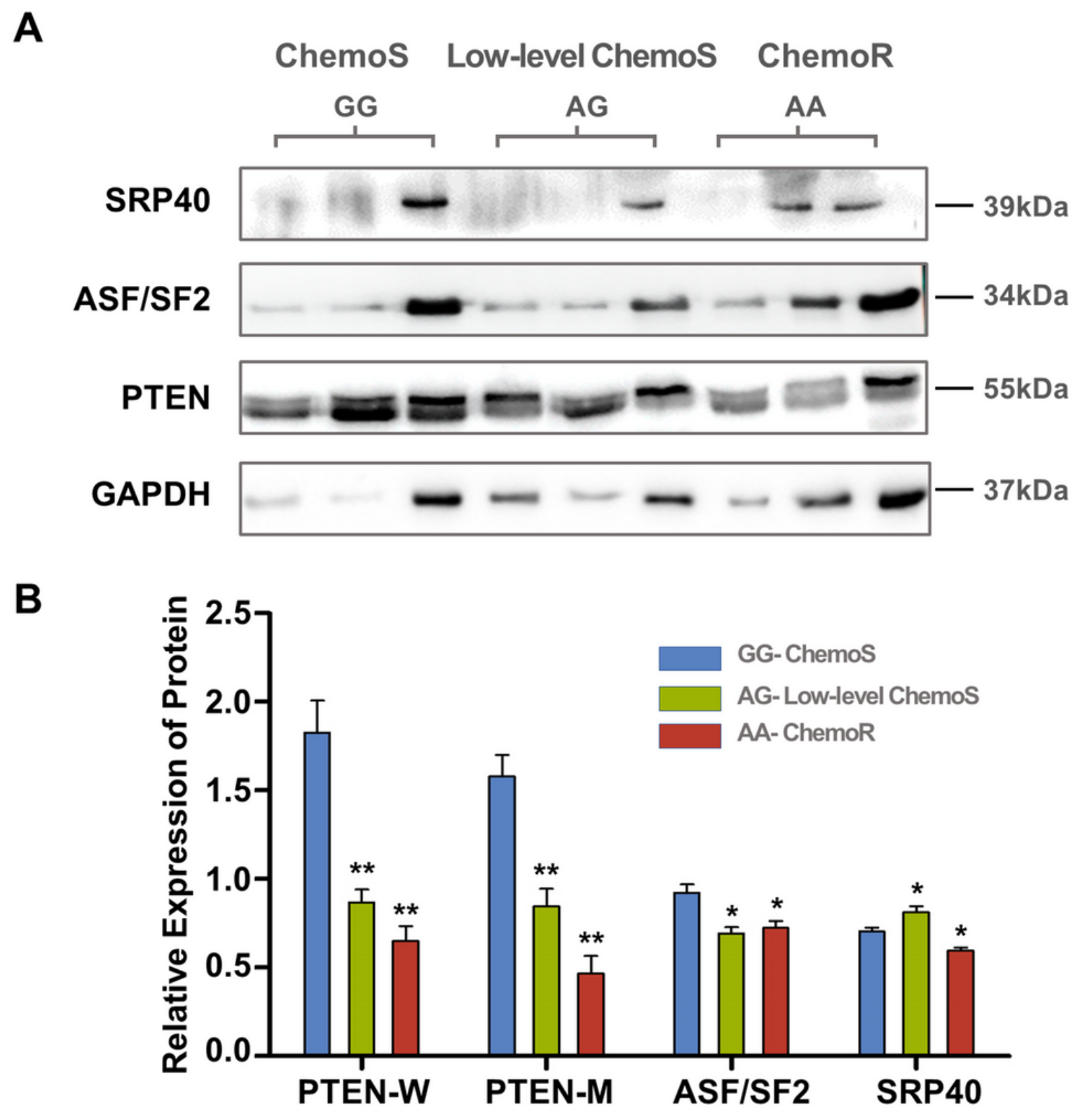

Figure 5

Protein expression of new isoforms of PTEN and PTEN in samples of breast cancer. (A) Protein expression of PTEN, ASF/SF2, SRP40; PTEN-W is the lower band (55KD), PTEN-M is the upper band. (B) Gray value analysis of protein expression of PTEN-W, PTEN-M, ASF/SF2, SRP40. 
A
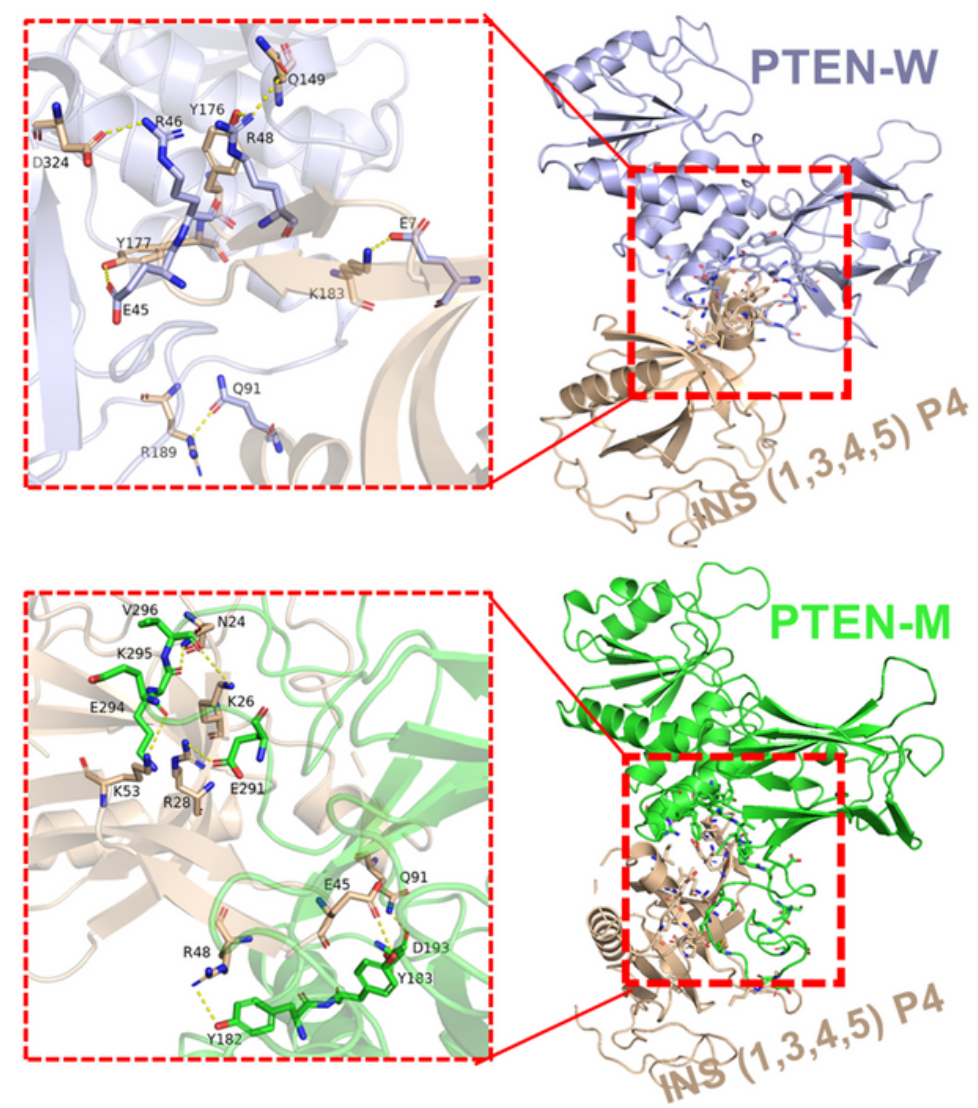

C

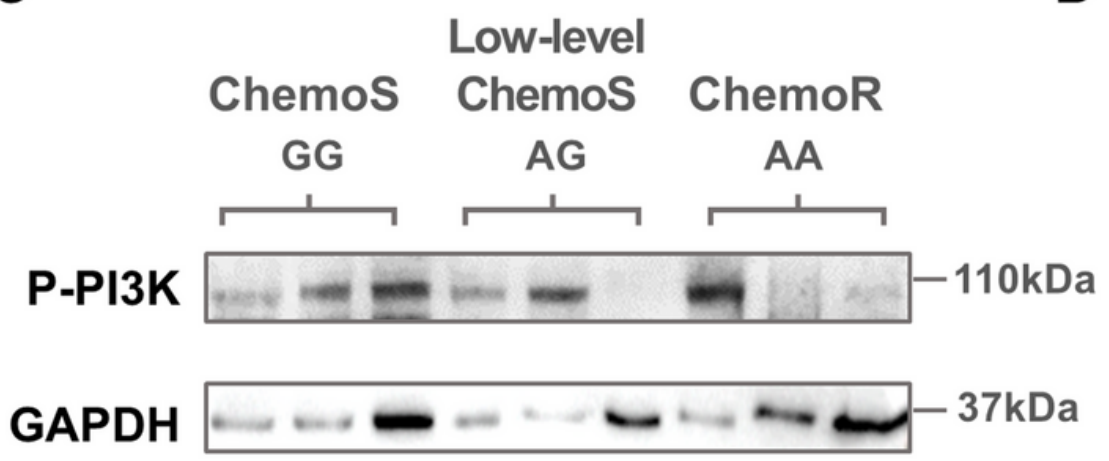

B

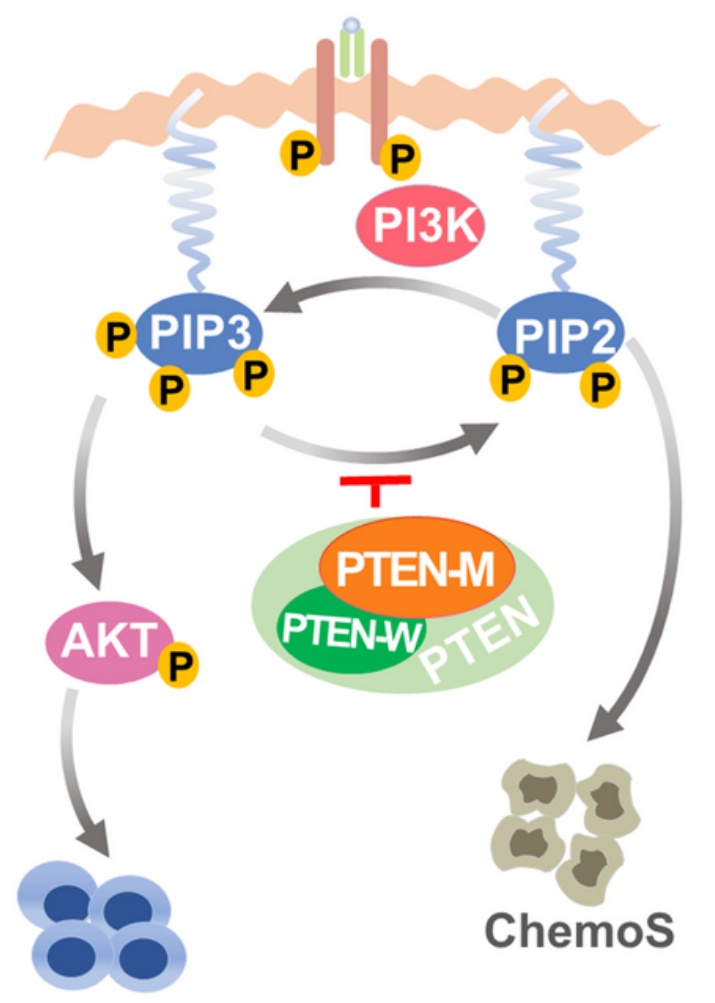

ChemoR

D

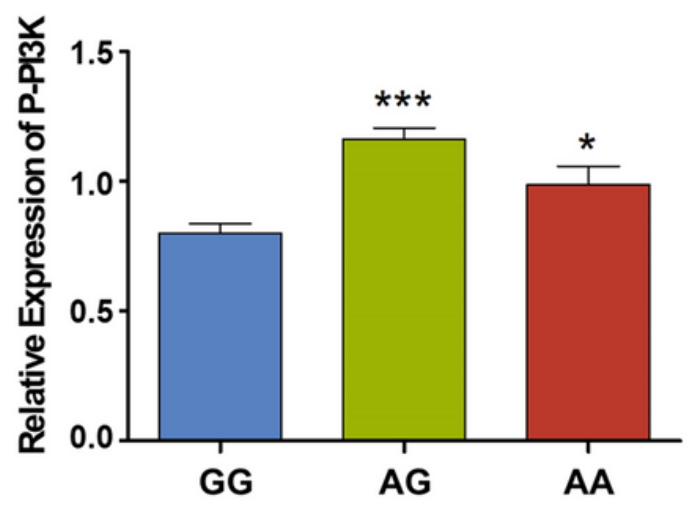

Figure 6

The difference response of wild and mutant PTEN isoforms to PI3K drug-resistance signalling pathway. (A) Model of INS $(1,3,4,5)$ P4 binding to the PTEN wild and mutant isoforms, INS $(1,3,4,5)$ P4 and PIP3 have the same domain (B) Model diagram of wild and mutant PTEN isoforms and PI3K resistance signaling pathways. (C) Protein expression of P-PI3K. According to the different genotypes (GG, AG, AA) of the samples, they are divided into chemosensitive, Low-level chemosensitive, chemoresistant groups. (D) Gray value of Protein expression of P-PI3K 


\section{$\because$}

234 patients enrolled (157 ChemoS and 77 ChemoR)

rs786204926 was analysed

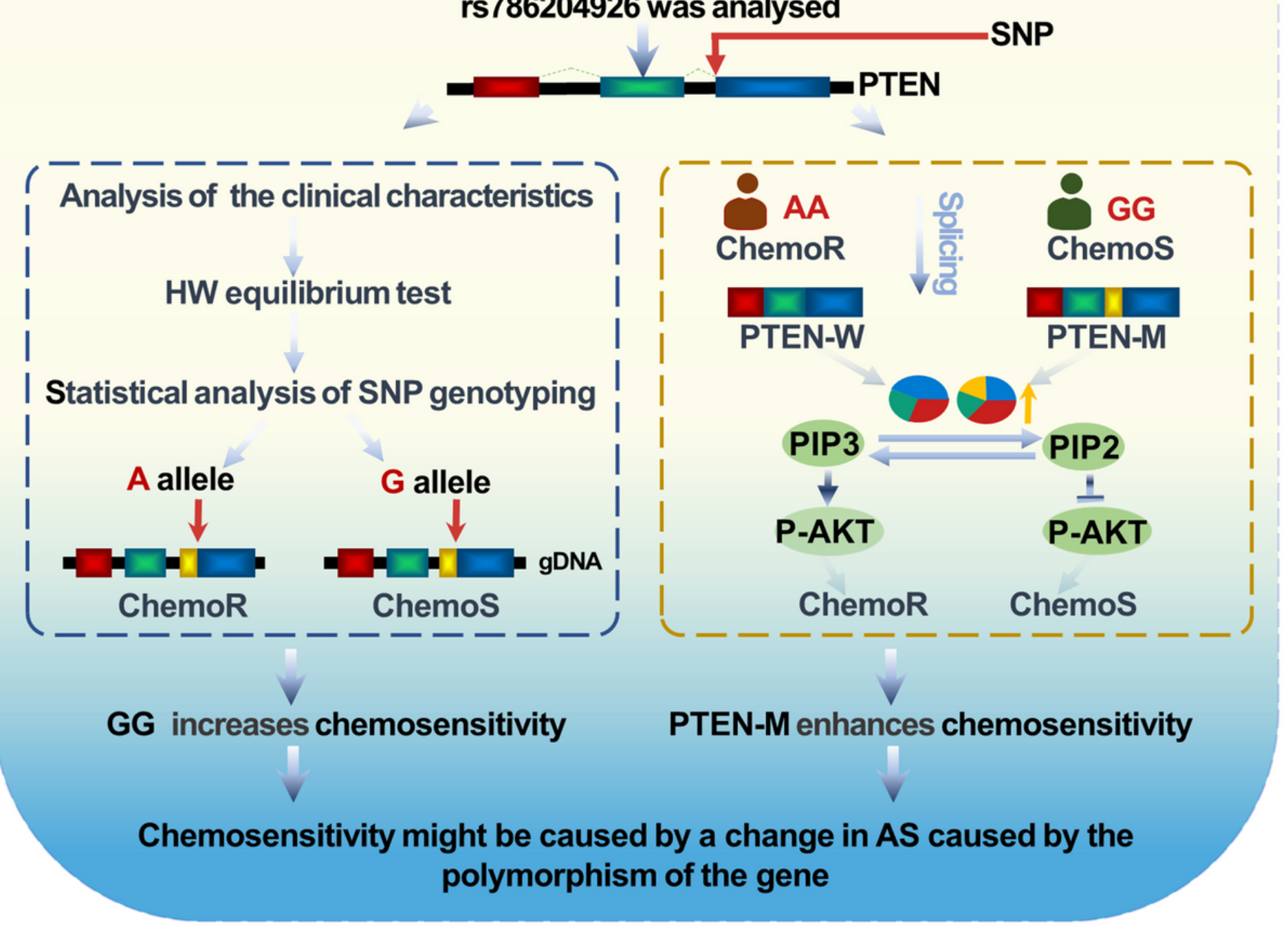

Figure 7

Schematic representation of mechanism of chemosensitivity in breast cancer

\section{Supplementary Files}

This is a list of supplementary files associated with this preprint. Click to download.

- SupplementaryTable14.docx 